EDUCATION

Research, Innovation and Solutions on-line ${ }^{(0)}$
PSYCHOLOGY

I+Dti
Electronic Journal of Research

in Educational Psychology

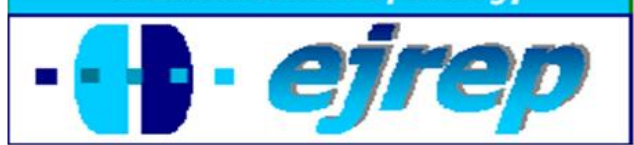

\title{
The Influence of Parents and Teachers on the Deep Learning Approach of Pupils in Norwegian Upper-Secondary Schools
}

\author{
Eyvind Elstad $^{1}$, Knut-Andreas Christophersen ${ }^{2}$ \\ \& Are Turmo ${ }^{3}$ \\ ${ }^{1}$ Department of Teacher Education and School Research, \\ ${ }^{2}$ Department of Political Science, \\ ${ }^{3}$ Department of Teacher Education and School Research, \\ University of Oslo, Oslo
}

\section{Norway}

Correspondence: Eyvind Elstad. P.O. Box 1099 Blindern, 0317 Oslo, Norway E-mail: eyvind.elstad@ils.uio.no

(c) Education \& Psychology I+D+i and Editorial EOS (Spain) 


\begin{abstract}
Introduction. The purpose of this article was to explore the influence of parents and teachers on the deep learning approach of pupils by estimating the strength of the relationships between these factors and the motivation, volition and deep learning approach of Norwegian 16year-olds.
\end{abstract}

Method. Structural equation modeling for cross-sectional survey data was used to estimate the path coefficients. A total of 1,112 students voluntarily participated. The analysis indicated that the teachers' perceived efforts to influence and stimulate the deep learning approach of the pupils had some effect.

Results. Parental efforts in this respect did not appear to have any noticeable influence on the pupils' motivation, volition or deep learning approach. Teacher pressure was found to influence the motivation and deep learning approach, and teachers can make conscious use of this effect in order to improve the students' performance.

Conclusion. For pupils who lack educational motivation, the teacher has an important function in motivating greater effort with schoolwork and stimulating a more effective deep learning approach. The current study provides new knowledge concerning the influence of teachers and parents on students' learning efforts.

Keywords: deep learning approach, youth, Norway, teacher pressure, parental influence 


\section{La influencia de padres y profesores en el enfoque de aprendizaje profundo en estudiantes de bachillerato de Noruega}

\section{Resumen}

Introducción. El propósito de este artículo es explorar la influencia de los padres y maestros en el enfoque profundo de los alumnos mediante la estimación de la fuerza de las relaciones entre estos factores y la motivación, la voluntad y el enfoque de aprendizaje profundo, en jóvenes noruegos de 16 años de edad.

Método. Se utilizaron modelos de ecuaciones estructurales de datos transversales de la encuesta se utilizo para calcular los coeficientes de trayectoria. Un total de 1.112 estudiantes han participado voluntariamente.

Resultados. El análisis indicó que los profesores perciben que la influencia y la estimulación del enfoque de aprendizaje profundo de los alumnos tuvo algún efecto. Los esfuerzos de los padres en este sentido no parece tener ninguna influencia notable en los alumnos, en cuanto a la motivación, la voluntad o el enfoque de aprendizaje profundo. Los profesores pueden hacer uso consciente de este efecto con el fin de mejorar el rendimiento.

Conclusión. Para los alumnos que carecen de motivación para la educación, el profesor tiene una función importante en la motivación de un mayor esfuerzo con el trabajo escolar y estimular un enfoque de aprendizaje profundo más eficaces. El presente estudio proporciona nuevos conocimientos sobre la influencia de los maestros y padres sobre los esfuerzos de aprendizaje.

Palabras clave: Enfoque de aprendizaje profundo, la juventud, Noruega, la presión de losmaestros, influencia de los padres. 


\section{Introduction}

The manner in which pupils approach their learning has been the focus of a great deal of educational research. Educational psychological research indicates two major learning approaches: "surface learning” and "deep learning” (Marton \& Säljö, 1984). A surface approach is associated with the repetitive and surficial memorising of details without any further analysis, while a deep approach is characterised by an intention to understand the meaning of an academic task and link the material to prior knowledge. Biggs (1987) suggested "achieving" as a third learning approach. Pupils who adopt a deep learning strategy are found to engage more in learning. The deep learning approach is often associated with learning outcomes that are higher in quality compared to those resulting from the surface learning approach (Bath \& Smith, 2009; Biggs, 1991; Entwistle, 1981; Phan, 2008; Phan \& Deo, 2007), although the results have not been clear-cut. However, Phan (2009) found a significant link between deep processing and academic performance among university students, while other researchers found that the deep approach is often a poor predictor of academic performance (Diseth \& Martinsen, 2003; Groves, 2005; Jones \& Jones, 1996; Provost \& Bond, 1997). To date, few studies have described the changes in these learning approaches. For instance, Biggs (1987) surprisingly found a decline in the deep and surface approaches between the ages of 14 and 16, and Eklund-Myrskog and Wenestam (1999) detected similar findings in a Finnish study. However, an explanation of this phenomenon has not yet been proposed.

Several contextual variables are expected to influence pupils' learning approaches. Cano and Cardelle-Elawar (2008) examined family-environment variables as predictors of learning strategies and academic performance. They found that pupils with better family intellectual climates held more mature beliefs about learning and, consequently, were more likely to take a deep learning approach and exhibit a better academic performance. In this study, the mean age of the participants was 13.90. However, little attention was paid to the transition between puberty and legal adulthood. The mid-teens represent this transitional phase.

Various research studies have been conducted on teaching approaches using different theories (i.e. orientations to teaching) (Kember \& Gow, 1994) and general approaches to teaching (Biggs, 1999; Prosser \& Trigwell, 1999). It is assumed that teachers' teaching approaches influence pupils' learning approaches in very complex ways. The culture and age of the pupils might influence their perceptions of the teaching. For instance, teacher-centred teaching was found to be correlated with a surface learning approach among students at Hong 
Kong universities, whereas it was found to be correlated with a deep learning approach for students in China (Leung, Lu, Chen, \& Lu, 2008).

\section{Background}

During childhood, it is expected that children's parents make decisions on their behalf (e.g. choosing a school). Society members expect parents to ensure that the child attends school (compulsory education in Norway lasts until the end of the tenth grade or age 16) and that they have food, clothing and security. Thus, the transition to upper-secondary school (which, in Norway, occurs between the ages of 15 and16) involves an increase in the child's rights to make decisions that influence his/her life. From this perspective, it is interesting to examine how the attempts of parents to influence the learning efforts of their 16-year-olds can influence the motivation, volition and use of learning strategies of the youth. The 16-year-olds are neither children nor adults, but rather somewhere in between. This study investigates this phenomenon in the grey area between childhood (in which decisions are made on one's behalf) and youth (an age at which society grants increased autonomy over decisions regarding learning).

Teachers represent another group of adults with whom children and young people have contact throughout their formative years. The expectations of the authorities regarding how teachers exercise their role have changed. For instance, during the 1990s, the motto for educational reform was that pupils should "have responsibility for their own learning" (Bjørgen, 1994). One of the goals expressed at the time was to "create an equality between pupil and teacher within a democratic learning organisation in which the pupils should be participants in decisions regarding the learning process" (NOU, 2003). It was an ambition that the pupils should participate in making decisions regarding the learning process: "[T]he Ministry of Education has long wished [that] pupils should to a greater degree work independently and in groups with questions that they themselves have developed" (Aftenposten, 2001). During the years following the turn of the century, the political signals regarding the role of the teacher changed in character. The line is now that it is important to "re-establish the authority of the teacher, discipline and academic ambitions as a basis for improved learning" (UFD, 2004). In addition, it is "important that the school and the teachers ensure an adequate pressure of work. [The school] is not to give pupils more co-responsibility than they are capable of taking and the individual teacher is to avoid giving way to the pupils" (White paper, 2003:55). Furthermore, political documents state that "[i]t is the task of the teacher to attain 
the goal of more learning in all subjects and to ensure that subject-based work provides the pupils with the best possible learning outcomes" (KD, 2008, pp. 12). Teachers are now (to a greater extent than previously) held responsible for the results of the school's activities: "[T]he teacher is to have a clearly-defined responsibility for what the pupils learn" (KD, 2008, pp.12). The background for this change in political intentions in regard to how the teacher's role is exercised is that international large-scale assessments (PISA, TIMSS, etc.) have shown disappointing results on Norway's part during the last decade. It is now a declared intention that teachers must improve their practical and professional skills, such as classroom leadership. In short, the teacher is to exercise more pressure in teaching and is to be a clear leader-figure for the youngsters. In the Læringsplakaten ("The Learning Declaration"), it is explicit that "schools are obliged to stimulate the pupils to develop their own learning strategies", with learning strategies referring to the pupils' conscious strategies regarding how they work with the curriculum materials (Weinstein \& Mayer, 1986). From this starting point, it is interesting to investigate how the pressure exerted by teachers can influence the motivation, volition and deep learning approach of pupils as an important learning strategy.

Once pupils reach their mid-teens, they are given greater autonomy as decision makers (Nielsen, 2009). It is assumed here that the pupils' own goals for their learning and the pupils' volition for the pursuit of their learning are central categories in the decision making process that informs strategically considered choices. This assumption has been supported by research that argues that motivation and volition are discrete categories (Gollwitzer, 1999). Furthermore, some research has shown that parents and teachers can exercise influence over the learning work of young people (research summarised in Hattie, 2009). In this article, we investigate the effect of teacher and parental pressures on the deep learning approach of 16year-old pupils in the first year of upper-secondary school (year 11, the first year of noncompulsory schooling). First, we present the theoretical framework that justifies the theoretical model which we built. We then give an account of the research design and research method and present the empirical results. Finally, we discuss these empirical results, including the strengths and weaknesses of the study as well as its implications for future research and practice.

\section{Theoretical Framework}

The idea behind the legislation and institutional practice for the expected behaviour of parents and teachers is that young pupils can benefit from constraints to their options (Elster, 
2000, p. 277; Thaler \& Sunstein, 2008). This idea (which is also in accordance with folk pedagogy) can be given theoretical confirmation by the idea of behaviourism with respect to the "shaping" of behaviour. That is, by means of rewards (but also punishments), behaviour can be influenced and, over a period of time, shaped (Skinner, 1953). Behaviourism's perspective is a positive one: upbringing can shape behaviour. This is also supported by neurobiological research into the connections between neurons (which become established as habits) (Thompson, 1994). Behaviourists' ideas of behavioural formation, however, have been criticised for neglecting the significance that learned active intention-creating activity can have for the learning process (Baar, 1986; Bruner, 1983; Gardner, 1985). The concept of the self-regulated behaviour of pupils reinforces this (Pintrich, 2000). Related to this branch of theory is the theory of self-determination (Ryan \& Deci, 2000). The basis of these theories is that it is important for the development of agency and the ability to accomplish that students set personal goals for learning (hereafter termed goal-driven motivation) and pursue strategies in order to achieve these goals (hereafter termed volition) (Boekaerts \& Corno, 2005). Some researchers have understood the latter as an implicit and almost natural consequence of goaldriven motivation (Zimmermann, 1998). Other researchers have isolated this as an independent factor that is referred to using several different labels: regulation of motivation (Wolters, 2003), self-discipline (Duckworth \& Seligman, 2005) and volition (Corno, 2000). We assume that motivation is primary and is put into action by means of consciously driven actions. The dependent variable in this study is the deep learning approach of pupils.

The term "learning strategy" refers to the mental process carried out by the pupil at a specific time, with the intention of improving learning. Several types of learning strategies have been suggested. For instance, surface strategies are strategies aimed at increasing the retention of relevant material (Marton \& Säljö, 1984). It has become widely acknowledged that the positive effects of these strategies for the pupil's understanding of academic material are limited. Therefore, we disregard surface strategies in the present study. Structural strategies, on the other hand, are intentional strategies aimed at perceiving the structure in the material that is to be learned. Elaboration (or generative strategies) is a term denoting strategies for integrating new material into existing knowledge. The use of meta-cognitive knowledge has also been referred to as a learning strategy, even though this is more a matter of personally assessing and reflecting upon one's own learning process. Unfortunately, research has provided limited empirical support to the maintenance of a detailed division of learning strategies (e.g. nine learning-strategy scales in Paul Pintrich's “The Motivated Strategies for Learning 
Questionnaire"). Even though we can argue from an empirical standpoint for a division between elaboration and structural strategies, it is difficult to find a clear empirical basis for maintaining this type of division (Duncan \& McKeachie, 2005). In this study, we accept the consequences of this and combine them into one concept termed the "deep learning approach". By this, we mean a depth-oriented strategy for promoting an understanding of the material to be learned. Consciousness of one's own learning process is something that we regard as important for the pupil's development towards being an independent individual capable of self-determination, as in relation to learning, we can easily fall into habits that are ineffective for attaining a good result. Following short-term goals to attain immediate pleasure and satisfaction can lead to a poor result in the long term. For this reason, conscious decisions requiring effort and input are often necessary to mobilise learners out of their immediate comfort zones (Elstad, 2006). This state of conscious effort might be experienced as uncomfortable or, at least, as less comfortable than achieving pleasure of the sort offered by, for instance, entertainment. The latter is relevant here because pupils in Norwegian uppersecondary schools are given PCs which they are supposed to make active use of in their learning. However, schools have internet access, and pupils, therefore, tend to face the temptation of being attracted by what the PC offers in terms of entertainment (Elstad, 2008; Krumsvik, 2006).

Goal-focused motivation is an important category in a cognition theory-based understanding of the prerequisites of the deep learning approach (Pintrich, 2000), while volition consists of strategic deliberations for delivering actions away from the comfortable and towards conscious effort (Ainslie, 2001). In our concept, external circumstances provide pupils with opportunities for pre-commitment as a tool for volition (Elster, 1979). Both parents and teachers can perform a function in encouraging such leanings towards effort in learning. It is also relevant that the individual learner can exercise control over these processes by using volitional learning strategies (NN, 2012). Here, we imagine a continuum from parental constraint (i.e. the determination of parents or teachers that one must follow) (Elster, 2000, p. 276) via libertarian paternalism (Thaler \& Sunstein, 2008) to complete self-determination (Ryan \& Deci, 2000). Libertarian paternalism is a more sophisticated variant: the teacher deliberately manipulates the options in order to ensure a particular result. The teacher's decisions about the amount of work required can be an element here, alongside the options that are presented to the pupil. It is, however, the pupil who chooses. The borderline between this and complete self-determination is indistinct. For instance, we can imagine various forms of 
persuasion on the part of either the teacher or the parent. For instance, either can play on feelings and relational duties. Ryan and Deci (2000)'s concept of introjected regulation can be viewed as a possible example. Game theory reveals a field of study in strategic interaction. For instance, brinkmanship can refer to the pressure which the teacher exerts by pushing the pupils in a particular direction while providing an outstretched hand for support (Schelling, 1960 , p. 200). Strategic moving is the art of changing the pupil's beliefs and choices in a manner that is favourable to the teacher, by influencing the pupil's expectations of how the teacher will behave (Schelling, 1960, p. 160). All of these (and more) can be elements in the teacher's toolbox (Elstad, 2002) that he/she uses to exert pressure in teaching (i.e. to get the pupil to do more than would otherwise be the case on the basis of short-term goals). The same techniques can, in principle, be used by parents to attempt to persuade their child to study more intensely than he/she would have done otherwise. We find it reasonable to believe that teachers and parents want to influence pupils' studies, but we have not found any attempts in the literature to estimate the strength in the statistical associations between these concepts for this age group. Our theoretical assumption is that the pressure exerted by parents (homework) and teachers (seatwork) on the learning intensity of pupils will yield direct and indirect results through influencing motivation and volition. The purpose of this article is to explore these relationships by estimating the strength of the relationship between the concepts.

\section{Objectives and Hypothesis}

The purpose of this article is to explore the influence of parents and teachers on the deep learning approach of pupils by estimating the strength of the relationships between these exogenous factors and the motivation, volition (mediators) and deep learning approach (endogenous variable) of Norwegian 16-year-olds. In this study, we understand the influence of parent and teacher pressure as an antecedent of the decisions taken by pupils, and we estimate the significance of these factors for 16-year-olds' motivation, volition and (indirectly) the deep learning approach. In a questionnaire-based survey, pupils were asked to consider a series of statements. With the help of structural equation modelling, we estimated the strength of the proposed causal processes by means of path coefficients. 


\section{Methods}

\section{Participants and procedure}

With the Knowledge Promotion school change initiative in Norway, there are 12 different study programmes in the upper-secondary school curriculum plan. All the programmes have a compulsory science course in the first year of upper-secondary school. In accordance with the Norwegian education authorities' focus on increasing students' interest in science, science was chosen as the focus subject in the survey. The subject is structured into primary areas, each of which contains embedded competence aims. Science has a number of competence aims after the second, fourth, seventh and tenth grades and after the first year of the academic and vocational study programmes offered in upper-secondary school. Students in the vocational programmes receive parts of the academic programme's science curriculum for the first year of upper-secondary school. However, the competence aims are the same within these areas. The main area of "the budding researcher" is compulsory for all students. Additionally, students study two main areas that the school designates as relevant to the study programme.

The empirical study that forms the basis for the analyses was completed with seven upper-secondary schools located in the Norwegian capital, Oslo. The research study was implemented with the help of a research assistant who travelled to the schools to administer an anonymous, paper-based questionnaire in the classes. In total, 48 science classes from 5 of the 12 different study programmes participated. A total of 1,112 students voluntarily participated. The survey response rate was high and close to 100 per cent. Table 1 shows the distribution of students according to the various study programmes. The table illustrates that the number of students enrolled in the academic programme is proportionally higher, yet the number of students in the sports programme is also significant. 
Table 1. The distribution of students in the various study programmes, including numbers of students and percentages

\begin{tabular}{lcc}
\hline Programme of study & Number of students & Percentage \\
\hline Academic programme & 805 & 73 \\
Sports programme & 167 & 15 \\
Music, dance and drama programme & 48 & 4 \\
Design and handicrafts programme & 40 & 4 \\
Electrician programme & 50 & 5 \\
\hline Total & 1,112 & 100 \\
\hline
\end{tabular}

The intake point average among the schools was about 40.9, and the intake point score was calculated as the sum of 11 marks after the tenth grade (scale from 1 to 6 ). This is somewhat higher than the average for all upper-secondary schools in Oslo (39.3). The intake point average among the seven schools varied between 37.5 and 44.2. Among the upper-secondary schools in Oslo, there is a variation between about 29 and 48 points. In other words, the upper-secondary schools in the sample had medium to high intake scores.

\section{Instruments}

The student questionnaire comprised questions on the deep learning approach, motivation, volition, teacher pressure and parental pressure. The focus was on academic aspects related to a specific school subject (as previously mentioned, science). Furthermore, we concurred with the governmental priority of increasing interest in science as a subject in school and at the university level (consider UFD, 2005).

The work was conducted within a classical test theoretical paradigm (Crocker \& Algina, 1986), where psychological constructs are operationalized through a set of individual questions that are asked of the students. The students were asked to respond to the questions using a five-point Likert scale with alternative response choices: Strongly disagree (1), Disagree (2), Neither agree nor disagree (3), Agree (4) and Strongly agree (5).

The following constructs based on the questionnaire were studied: three student internal constructs (volition, motivation and the deep learning approach) and two student external constructs (teacher pressure and parental pressure). Table 2 provides an overview of the constructs under study along with example items. 
Table 2. Constructs with example items.

\begin{tabular}{ll}
\hline Construct and Alpha & \multicolumn{1}{c}{ Example items } \\
\hline $\begin{array}{l}\text { Pupil constructs } \\
\text { Volition }(\alpha=.77)\end{array}$ & $\begin{array}{l}\text { Mainly, I do my homework at the last minute } \\
\text { (reversed). }\end{array}$ \\
Motivation $(\alpha=.81)$ & $\begin{array}{l}\text { It is important for me to learn as much as pos- } \\
\text { sible in science this school year. }\end{array}$ \\
Deep learning approach $(\alpha=.81)$ & $\begin{array}{l}\text { I try to see the connection between what I } \\
\text { learn in science and what I already know. }\end{array}$ \\
Exogenous factors & $\begin{array}{l}\text { The science teacher makes high demands of us } \\
\text { students. }\end{array}$ \\
Teacher pressure $(\alpha=.67)$ & $\begin{array}{l}\text { My parents ensure that I do my homework } \\
\text { when I come home from school. }\end{array}$ \\
\hline
\end{tabular}

\section{Data analysis}

The analyses were conducted using SPSS 18 and AMOS 18. The analysed sample consisted of 1,037 students after excluding the students with missing values. To assess the measurement reliability of the indicators for each of the subscales, Cronbach's alpha was used. Alpha coefficients of .70 or higher were considered acceptable (Nunnally et al., 1994). Cronbach's alpha was below .70 for one subscale (teacher pressure) and above .70 for four subscales. Thus, the Cronbach's alpha values ranged from .67 to .81, and the internal consistency was considered acceptable.

Construct validity was assessed theoretically and empirically. Firstly, all items were analysed one-by-one as considered to be substantively relevant indicators of their respective constructs. We concluded that the face validity was acceptable. Next, confirmative factor analysis (CFA) was used to empirically assess the construct validity of teacher pressure (four items), learning strategy (seven items) and the total measurement model. The assessments were based on the standard criteria $(\mathrm{p}>.05$; NFI, GFI and TLI > .95; and RMSEA < .05) for good fit, and $\mathrm{p}>.05$; NFI, GFI and TLI >.90; and RMSEA < .10 for acceptable fit between the model and the data (Blunch, 2008; Kline, 2005). The fit indices for the TP-scale were $\mathrm{p}\left(\chi^{2}\right.$ $=.075)$ with degrees of freedom $(\mathrm{df})=1$, RMSEA $=.046$, GFI $=.998$ and TLI $=.979$, allowing for covariance between items 1 t85 and 1t88. For the LS-scale, the values were $p(\chi 2=$ $.000), \mathrm{df}=14, \mathrm{RMSEA}=.054, \mathrm{GFI}=.985$ and TLI $=.966$. For the total measurement model, the values were $\mathrm{p}(\chi 2=.000, \mathrm{df}=159), \mathrm{RMSEA}=.038, \mathrm{GFI}=.963$ and TLI $=.951$. The CFA indicates acceptable empirical construct validity. 


\section{Results}

The assessments of the structural models were based on the same fit indices and the same fit criteria as the measurement model. The fit indices (Figure 1) were considered acceptable due to $\mathrm{p}(\chi 2=.000, \mathrm{df}=159, \mathrm{RMSEA}=.038, \mathrm{GFI}=.963$ and TLI $=.951$. Table 3 shows the effect components based on the structural model. This table shows that $23 \%$ of the variance in the dependent variable is statistically explained by the independent and mediating variables in the model.

Table 3. Estimated effect components for the structural model with "deep learning approach" (LS) as the endogenous variable.

\begin{tabular}{lccccc}
\hline & Correlation & $\begin{array}{c}\text { Total } \\
\text { effect }\end{array}$ & $\begin{array}{c}\text { Direct } \\
\text { effect }\end{array}$ & $\begin{array}{c}\text { Indirect } \\
\text { effect }\end{array}$ & $\begin{array}{c}\text { Spurious } \\
\text { effect }\end{array}$ \\
\hline Teacher pressure & .28 & .28 & .18 & .10 & .00 \\
Parental pressure & .06 & .05 & .04 & .02 & .00 \\
Volition & .19 & .08 & .08 & .00 & .11 \\
Motivation & .44 & .39 & .38 & .02 & .05 \\
\hline $\mathrm{R}^{2}$ (deep processing approach) $=.23$ & & & & \\
\hline
\end{tabular}




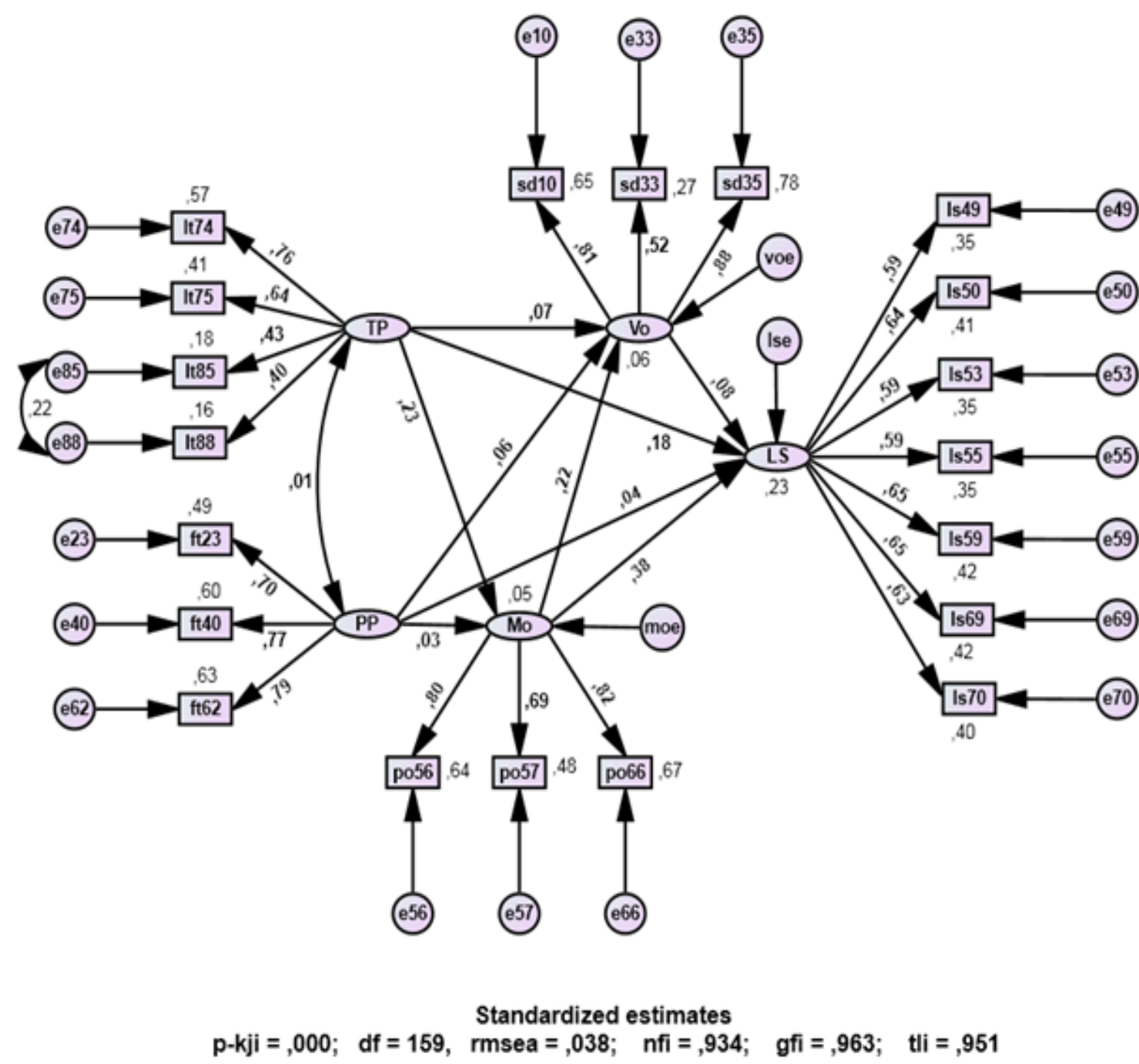

Figure 1. The structural model with estimated standardised coefficients. $(T P=$ Teacher pressure, $P P=$ Parental pressure, Vo $=$ Volition, Mo $=$ Motivation, $L S=$ Deep learning approach $)$

\section{Discussion}

If the path coefficients given in Figure 1 reflect causal processes, these empirical results indicate that the actual influence of parents' supervision on the schoolwork of the children around the age of 16 is limited. In this case, such a result emphasises that the emerging independence of the youth in terms of schoolwork begins early in the Norwegian social context. Moreover, this is in line with the structural expectations of the parental role with respect to pupils in Norwegian upper-secondary school in the sense that parents do not have the right to obtain information about their children's studies and learning requirements at school. The parents' rights to make decisions for their children change during the mid-teens, but vary by 
country and by function. One aspect of these changes concerns the rights of the parents to choose a school. Most Norwegian 12- and 13-year-olds change schools when they transition from seventh to eighth grade. When the offer of a school place is given to each of these students in Norway, it is sent by the local authority to the child's parents, who have the right to decide whether they will accept the local authority's offer or apply for a place at another school. When students aged 15-16 apply to upper-secondary school, however, the authorities only address them directly, and the students' receive a password with which they can handle their own online application procedure. Without the permission of the child, the parents have no insight into the process and, therefore, have no formal influence over their child's choice. The legal foundation of this practice is "Act Relating to Children and Parents", section 32: "Children who are aged 15 years decide the question of choice of education by themselves" (BLD, 1981). Another example relates to parental influence over homework. Most Norwegian schools use work plans as a medium for disseminating information about all the learning work that is carried out during a given period (e.g. a one- or two-week period) (Klette, 2007). In addition to these detailed work plans, there are generally long-term plans that provide information about the learning progression over an entire term or school year. In lower-secondary school, parents are kept up to date about their children's work plans (which include concrete information about homework, goals for the various lessons, etc.) and are expected to take an active interest in their children's homework. The vast majority of upper-secondary schools in Norway have an entirely different practice. Normally, parents do not have any direct insight into the work plans (which are password-protected by the school) or matters related to the school's expectations of the pupils' work. In other words, the transition to upper-secondary school marks a divide in relation to the degree to which parents are kept informed about the school's plans and expectations. This division is also reflected in Norwegian law. By law (BLD, 1981), a person over 16 years of age receives extended rights in a number of areas (e.g. increased rights regarding the management of money). In fact, trials are being held regarding the participation of 16-year-olds in political elections. Upon reaching the age of 18, the pupil is of age and is an adult (although the parents' obligation to provide housing continues until the completion of upper-secondary school). A taste of the political role of citizenship also occurs through the medium of school elections (e.g. political elections that function as trial versions). Through this background, we are able to understand the parents' minimal influence on homework. 
The pathways from teacher pressure on pupil motivation and the deep learning approach indicate moderate values (Figure 1). As mentioned above, this finding is in line with other research concerning the significance of teachers in the learning processes of pupils (Hattie, 2009). The survey was carried out about four to five months after the start of uppersecondary school, and it documents an influence after a relatively short initial period within a three-year course. At the same time, this study indicates that while the influence is not a strong one, it is present. This suggests that teachers can influence the motivation, volition and deep learning approach of pupils by using suitable tools for this purpose. The Norwegian authorities have emphasised teachers' ability to stimulate pupils' learning strategies, and our study provides some empirical evidence to claim that this does, in fact, happen.

\section{Avenues for Further Research}

There is a need to explore the relationship between environmental variables (e.g. parents and teachers) and pupils' learning approaches. More longitudinal research is needed to address the complex interaction dynamics between parents' and teachers' intentional influence and pupils' motivation and volition, and the associated effects on learning approaches. There are a number of unaddressed issues in this area. Another interesting avenue for future research is the possible differences between pupils' learning approaches in different cultures. In conclusion, all these areas of research on the antecedents of deep learning approaches warrant further exploration in various schooling contexts. Learning approaches tend to be context and age dependent.

\section{Strengths and Limitations}

In terms of strengths, this study was carried out with a relatively large sample, and there was very little leakage during the execution of the empirical survey. Other than those who were ill at the time of the survey, all the invited pupils took part. This means that the statistical conclusion validity (Shadish, Cook, \& Campbell, 2002) is relatively strong. No significant differences were found between the pool of pupils who took part and other Norwegian pupils; however, we cannot simply assume that the findings apply to students from other school cultures. The psychometric characteristics of the structural model had good fitness characteristics, which is also one of the strengths of the study. In addition, the model was theory generated, which suggests that the estimated path coefficients reveal causality. However, the contributions of this study should also be viewed in light of several limitations. First, it should be emphasised that relatively little quantitative research has been carried out on youth 
cultures in Norwegian schools. A cross-sectional study, thus, only represents a static image of a phenomenon. It is inherently true that statistical associations do not imply causality. We can confidently state that motivation precedes volition and that volition precedes the deep learning approach. However, it can also be argued that effects from, for instance, the teacher's classroom management and leadership towards learners operate in the opposite direction to that assumed in our hypothetical model. More research along the same lines will improve our understanding of the assumed causal relationships and of the mechanisms that we assume to be responsible for what we are measuring.

The relation between teachers' academic pressure $\rightarrow$ motivation $\rightarrow$ volition $\rightarrow$ the deep learning approach might not be linear. The functioning of academic pressure might be lower than an optimal value of pressure. If so, one could see a positive linear relation between academic pressure and the motivation and deep learning approach of pupils. On the other hand, if the academic pressure is higher than the optimal value, one could possibly identify a negative relation between academic pressure and pupil reactions (Creemers \& Kyriakides, 2008, p. 216). However, Lee and Smith (1999) found that school academic pressure is positively related to gains in pupil achievement in American schools. We believe that this is also true in the case of 16-year-olds in Norwegian schools.

Furthermore, there is a need to include factors from outside the school system in order to study the kinds of factors that influence the mobilisation of effort on the part of learners. One challenge in relation to measuring such factors is that measurement becomes increasingly difficult in proportion to the remoteness of the factor in the hierarchical organisation of the educational sector.

Our empirical material covers seven schools in Oslo. Hence, our material is not sufficiently comprehensive to study the differences between various types of Norwegian schools in a meaningful statistical analysis. Another possible improvement would be to examine some cases in depth in order to attain a better understanding of the phenomena being studied.

There is a need to view the results of such surveys in tandem with qualitative studies of teacher-learner interactions and parent-youth interactions. Contrasting case studies are an interesting approach (Yin, 2008). Studying the dynamics within a school is an interesting but demanding research approach. Controlled experiments are beyond the realms of possibility for educational researchers, but studying the development processes in two schools that, in many respects, have substantial similarities apart from the one aspect being studied could set 
us on the trail of causal processes (Shadish et al., 2002). Longitudinal and quasi-experimental studies of this sort are needed in order to come closer to inferences about causality.

A further limitation of this study was the use of self-reported questionnaire data. The subjective component of such data is undeniable. Independent judgements can provide interesting data about a learner's perceived conceptions and attitudes, but it is difficult to carry out this process while honouring the promise of anonymity. A further limitation is that we did not have the opportunity to couple pupils' subjective self-reporting with objective data. Norwegian regulations make this type of connection between register data (which is not found to any great extent) difficult to carry out.

\section{Implications for Practice}

Despite its limitations, this study contributes to our understanding of the antecedents of the deep learning approach among Norwegian 16-year-olds. If the associations between the independent and the dependent variables represent causal relationships, our findings might have implications for practice.

Firstly, this study provides evidence suggesting that teachers' extensive work to encourage pupils to increase learning intensity has some effect on the motivation and deep learning approach of the pupils. In other words, the teacher has a significant influence on the study practices of 16-year-olds. This emphasises that our study appears to support the importance that has been attributed to the teacher in recent policy documents related to Norwegian educational policy. Even though our empirical results suggest that parental pressure does not seem to exert any noticeable influence, this does not mean that parents have no significance in relation to the academic lives of 16-year-olds. Parents can play an important role in their children's lives through relationship building and by providing the social adhesive that is found within a family. We reiterate that our model is parsimonious and that a richer theoretical model might have revealed parental influence expressed in other ways than those captured in our model.

\section{Conclusions}

We must conclude that teachers appear to exert a significant influence on the deep learning approach of pupils, both directly and indirectly, through influencing pupil motivation. This reinforces the importance of teachers thinking through how they exercise their role such that the pupil can make use of the potential positive influence that the teacher is able to 
exert. The age of 16 represents a transitional period between puberty and adulthood. The Norwegian authorities should continuously follow up on the work of making teachers aware of their potential influence. Another conclusion must be that parental pressure on pupils' schoolwork appears to have a rather modest influence in the terms in which this was measured in our empirical survey. This might be understood as a depressing result, but at the same time, we emphasise that the parental role can exercise an influence through channels other than those that have been captured here.

\section{References}

Ainslie, G. (2001). Breakdown of will. Cambridge: Cambridge University Press.

Baar, B. (1986). The cognitive revolution in psychology. New York: Guilford.

Bath, D. M., \& Smith, C. D. (2009). The relationship between epistemological beliefs and the propensity for lifelong learning. Studies in Continuing Education, 31, 173-189.

Biggs, J. (1987). The Learning Process Questionnaire (LPQ): Manual. Hawthorn, Victoria: Australian Council for Educational Research.

Biggs, J. (1991). Approaches to learning in secondary and tertiary students in Hong Kong: Some comparative studies. Educational Research Journal, 21, 46-58.

Biggs, J. (1999). Teaching for quality learning at university. Buckingham: Open University Press.

Bjørgen, I. A. (1994). Ansvar for egen laring. Trondheim: Tapir Forlag.

BLD (1981). Lov om barn og foreldre. Oslo: Barne- likestillings- og inkluderingsdepartementet.

Blunch, N. J. (2008). Introduction to structural equation modelling using SPSS and AMOS. London: Sage.

Bruner, J. (1983). In search of mind. New York: Harper \& Row.

Cano, F., \& Cardelle-Elawar, M. (2008). Family environment, epistemological beliefs, learning strategies, and academic performance: A path analysis. In K. M. S. Khine (Ed.), Knowing, knowledge and beliefs: Epistemological studies across diverse cultures. (pp. 219-239), New York: Springer.

Corno, L. (2000). Special double issue on conceptions of volition: Theoretical investigation and studies of practice. International Journal of Educational Research, 33, 659-663. 
Creemers, B. P. M., \& Kyriakides, L. (2008). The dynamics of educational effectiveness: A contribution to policy, practice and theory in contemporary schools. Abingdon, UK: Routledge.

Crocker, L., \& Algina, J. (1996). Introduction to classical and modern test theory. Fort Worth: Harcourt Brace Jovanovich College Publishers.

Diseth, Å., \& Martinsen, Ø. (2003). Approaches to learning, cognitive style, and motives as predictors of academic achievement. Educational Psychology, 23, 195-207.

Duckworth, A. L., \& Seligman, M. E. P. (2005). Self-discipline outdoes IQ in predicting academic performance of adolescents. Psychological Science, 16, 939-944.

Duncan, T. G., \& McKeachie, W. J. (2005). The making of the Motivated Strategies for Learning Questionnaire. Educational Psychologist, 40, 117-128.

Eklund-Myrskog, G., \& Wenestam, C. G. (1999). Student approaches to learning in Finnish general upper-secondary school. Scandinavian Journal of Educational Research, 43, $5-18$.

Elstad, E. (2006). Understanding the nature of accountability failures in the technology-filled classroom: Disaffected students and teachers who give in. Journal of Curriculum Studies, 38, 459-481.

Elstad, E. (2008). Towards a theory of mutual dependency between school administrators and teachers. Bargaining theory as research heuristic. Educational Management, Administration and Leadership, 36, 383-404.

Elster, J. (1979). Ulysses and the sirens. Cambridge: Cambridge University Press.

Elster, J. (2000). Ulysses unbound. Cambridge: Cambridge University Press.

Entwistle, N. J. (1981). Styles of learning and teaching: An integrative outline of educational psychology. Chichester: Wiley.

Gardner, H. (1985). The mind's new science. A history of the cognitive revolution. New York: Basic Books.

Gollwitzer, P. M. (1999). Implementation intentions: Strong effects of simple plans. American Psychologist, 54, 493-503.

Groves, M. (2005). Problem-based learning approach: Is there a relationship? Advances in Health Science Education, 10, 353-405.

Hattie, J. (2009). Visible Learning. A synthesis of over 800 meta-analyses relating to achievement. London: Routledge.

Jones, A. \& Jones, D. (1996). Student orientation to independent learning. Higher Education Research and Development, 15, 83-96. 
KD (2008) The Teacher: The role and education. White Paper no. 11. Oslo: Ministry of Education.

Kember, D., \& Gow, L. (1994). Orientations to teaching and their effect on the quality of student learning. Journal of Higher Education, 65, 58-74.

Klette, K. (2007). Bruk av arbeidsplaner i skolen - et hovedverktøy for å realisere tilpasset opplæring? Norsk Pedagogisk Tidsskrift, 91, 344-358

Kline, R. B. (2005). Principle and practice of structural equation modelling. New York: Guilford.

Krumsvik, R. (2006). ICT in the school. ICT-initiated school development in lower secondary school. Bergen: University of Bergen.

Lee, V. E., \& Smith, J. B. (1999). Social support and achievement for young adolescents in Chicago: The role of school academic press. American Educational Research Journal, $36,907-945$.

Leung, M. Y., Lu, X., Chen, D., \& Lu, T. (2008). Impacts of teaching approaches on learning approaches of construction engineering students: A comparative study between Hong Kong and mainland China. Journal of Engineering Education, 4, 135-145.

Marton, F., \& Säljö, R. (1976). On qualitative differences in learning. I. Outcome and process. British Journal of Educational Psychology, 46, 4-11.

Nielsen, H. B. (2009). Skoletid. Oslo: Universitetsforlaget.

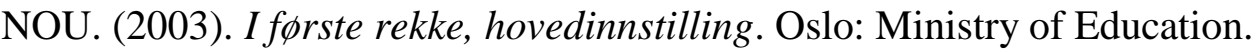

Nunnally, J. C., \& Bernstein, I. H. (1994). Psychometric theory. New York: McGraw-Hill.

Phan, H. P. (2008). Predicting change in epistemological beliefs, reflecting thinking and learning styles: A longitudinal study. British Journal of Educational Psychology, 78, 75-93.

Phan, H. P. (2009). Amalgamation of future time orientation, epistemological beliefs, achievement goals and study strategies: Empirical evidence established. British Journal of Educational Psychology, 79, 155-173.

Prosser, M., \& Trigwell, K. (1999). Understanding learning and teaching: The experience in higher education. Hong Kong: Open University Press.

Provost, S. C., \& Bond, N. W. (1997). Approaches to studying and academic performance in a traditional psychology course. Higher Educational Research and Development, 16, $309-320$

Ryan, R. M., \& Deci, E. L. (2000). Self-determination theory and the facilitation of intrinsic motivation, social development, and well-being. American Psychologist, 55, 68-78. 
Schelling, T. C. (1960). The strategy of conflict. Cambridge: Harvard University Press.

Shadish, W. R., Cook, T. D., \& Campbell, D. T. (2002). Experimental and quasiexperimental designs for generalized causal inference. Boston: Houghton-Mifflin.

Skinner, B. F. (1953). Science and human behavior. Englewood Cliffs, NJ: Prentice Hall.

Pintrich, P. R. (2000). The role of goal orientation in self-regulated learning. In M. Boekarts, P. R. Pintrich, \& M. Zeidner (Eds.), Handbook of self-discipline (pp. 450-502), San Diego: Academic Press.

Thaler, R., \& Sunstein, C. R. (2008). Nudge. Improving decisions about health, wealth, and happiness. New Haven \& London: Yale University Press.

Thompson, R. F. (1994). Behaviorism and neuroscience. Psychological Review, 101, 259265.

UFD (2004). Press Release. May 14, 2004. Oslo: Ministry of Educarion and Research.

Weinstein, C., \& Mayer, R. (1986). The teaching of learning strategies. In M. C. Wittrock (Ed.), Handbook of research on teaching (pp. 315-327). New York: Macmillan.

Wolters, C. (2003). Regulation of motivation: Evaluating an underemphasized aspect of selfregulated learning. Educational Psychologist, 38, 189-205.

Yin, R. K. (2008). Case study research: Design and methods (4th ed.). New York: Sage.

Zimmerman, B. J. (1998). Developing self-fulfilling cycles of academic discipline: An analysis of exemplary instructional models. In D. H. Schunk \& B. J. Zimmerman (Eds.), Self-regulated learning. From teaching to self-reflective practice (pp. 1-19), New York: Guilford. 